\title{
LA POLICITACIÓN EN EL DERECHO ROMANO Y SU CONEXIÓN CON LA LEGISLACIÓN MODERNA DEL DERECHO PÚBLICO: Enfoque Aplicado a la Revocatoria de Mandato de las Autoridades Municipales en Colombia, Una Aproximación $^{6}$
}

Carmelo Ramón Marsiglia Hernández camaher07@hotmail.com

\begin{abstract}
Resumen
Este artículo referido a 16-D.50.1.2.3 Ulpianus libro quarto disputationum, pollicitatio, promesa aun no aceptada, solamente válida en contados casos, como en el derecho público, esto es, cuando se hacía una promesa a una ciudad, lo que para el caso ha de considerarse que al no existir acuerdo entre las partes, esa figura de la pollicitatio, no es equiparable a un contrato o convenio, bien preparatorio o de promesa; la validez de su aplicabilidad desde la óptica del derecho comparado y su conexión con la legislación moderna del derecho público: es el enfoque aplicado a la revocatoria de mandato de las autoridades territoriales en Colombia, concordante con la aplicabilidad de los principios generales del derecho internacional, dada la naturaleza que en el ordenamiento Civil y Comercial Colombiano como Oferta hoy tiene; interesa, su validez a manera de interpretación, caso aplicado al derecho público, como REVOCATORIA de mandato, para las autoridades locales de elección popular (municipales, distritales y departamentales), conforme a la Constitución (artículo 103) y la ley (134 de 1994)
\end{abstract}

Palabras Claves: Policitación; Desarrollos normativos civil y de derecho público de la policitación; Programas de Gobierno como promesas, Revocatoria de Mandato, Causales de Revocatoria.

\section{Introducción}

Como profesionales del derecho, al igual que ayer, hoy y siempre, esta disciplina del conocimiento humano insta a estar preparados para intervenir de manera activa en variedad de casos, para cuya evaluación, análisis, diagnósticos y soluciones, de manera inmediata y de primera mano no estamos preparados para encarar, a diferencia de lo que suele ocurrir con los profesionales de la medicina, por

${ }^{6}$ Corresponde este escrito a un ensayo que como estudiante de III Semestre de la Maestría en Derecho VIII Cohorte Universidad Sergio Arboleda de Bogotá, sobre la asignación académica DERECHO COMPARADO DE LAS OBLIGACIONES, presentara al Dr. Juan Manuel Blanch Nogues profesor titular de la asignación, en razón a la importancia que para las autoridades municipales que inician periodo constitucional 2015-2019 tiene la figura de REVOCATORIA DE MANDATO, es por lo que se hace y ve necesario su publicación. 
hacer referencia a otra de las disciplina tan antigua como aquella, quienes en la etapa de formación académica son entrenados de manera meticulosa y dotados de reglas técnicas para el estudio de los síntomas, análisis de exámenes y elaboración de diagnósticos que le conducen al tratamiento del paciente y sus patologías; a nosotros, como abogados solo se nos da, de manera muy general un conocimiento de la disciplina, al menos en nuestra realidad regional (Montería, con cuatro Facultades de Derecho) que sin lugar a dudas, constituye una herramienta necesaria para el ejercicio de la profesión, pues como se sabe, no solo es necesario conocer el derecho, sino sus principios y ello aun no es suficiente; la falta a veces de una formación práctica con sólidos fundamentos filosóficos de análisis de caso, como las ilustrada por el titular de la asignación, para el caso las referidas al concepto romano del contrato ${ }^{7}$ nos lleva con mucha y diciente frecuencia a confundir "los análisis de los problemas (y los procesos que ello implica) con los de toma de decisiones y la valoración de los hechos, con la aplicación de las normas jurídicas, que a lo largo de la tradición y evolución romanística del derecho se nos indica, se ha construido y deberá seguirse construyendo la idea precisa a la que en los términos de lhering ${ }^{8}$ determine, precise y concretice la finalidad última perseguida por el derecho, es decir la consecución del bienestar del hombre en todos los campos, lo que equivale a afirmar, su utilidad para el individuo y la sociedad.

En esa tarea, se tiene claro y plena conciencia de que el orden jurídico debe ser visto y analizado hoy, desde diversos y variados puntos de vista: el del legislador, el del Juez, el del abogado en ejercicio, el del profesor, el del usuario, el del historiador, el del economista, el del administrador (público o privado), el del filósofo, el de sicólogo, el del comunicador social (por lo de la teoría Hebermesiana, hoy en pleno furor y boga), el del sociólogo y otros; para el caso en concreto, se aborda desde la perspectiva del abogado en ejercicio, lo cual se traduce en una aproximación de carácter técnico, esto es, sobre la base y necesidad de abandonar el análisis exclusivamente normativo que en el derecho civil y comercial tiene hoy la figura de la Policitación, emprender una aproximación desde la perspectiva del razonamiento jurídico fundado en los principios generales del derecho, comprendiendo la relatividad de los puntos de vista respecto del tema y su adopción integral

\footnotetext{
${ }^{7}$ Véase Blanch Nogués Juan Manuel - Tema 22 Concepto Romano del Contrato 16-D D.50.1.2.3

${ }^{8}$ Precursor de la jurisprudencia de los intereses, citación que de su obra -Espíritu del Derecho Romanoll hace J.L. Monereo Pérez, Estudio Preliminar; citado por Blanch Nogués Juan Manuel —La tradición Romanística. Memorias de cátedrall págs. 34 y 35
} 
El ensayo se desarrolla básicamente en tres (3) partes, a saber:

Resumen

Introducción

1. Ubicación de la aproximación al tema.

2. Policitación u oferta en el ordenamiento jurídico moderno

3. Planteamiento del enfoque aproximado y aplicado de la Policitación en el concepto del tema de derecho Público en Colombia "Revocatoria de mandato de las autoridades locales en Colombia

1. UBICACIÓN DE LA APROXIMACION AL TEMA. Como se indicó en el resumen o summary de este escrito, la figura de la policitación tomada del más antiguo derecho romano clásico ${ }^{9}$ tiene su explicación aproximada y deviene de los términos contrahere y contractus, que desde ese periodo, siendo claras las distinciones entre CONTRATO Y PACTO, no indicaban ser fuentes de las que nace la obligación, sino la propia obligación, en las que el consentimiento, en el entendido y significado de la expresión "convenir" hace referencia solo a aquellas obligaciones que surgen de la convención y en la que basa el significado de contractus o contrato que acogió la compilación Justinianea y que hoy persiste en el derecho moderno y contemporáneo. En ese sentido y de cara a centrar entonces el análisis de la aproximación del ensayo al objeto propuesto, conveniente es conceptuemos, distingamos y diferenciemos las definiciones del contrato y de la policitación; en efecto, aquel, siguiendo la conceptualización de Robert Joseph Pothier ${ }^{10}$ encierra el concurso de voluntades de dos personas de las cuales una promete alguna cosa a la otra, y ésta acepta la promesa que aquella le ha hecho; en tanto que la policitación asevera el autor descrito es la promesa que no ha aceptado aun aquel a quien se ha hecho (pollicitatio est solius offerentis promissum).

Afirma Pothier ${ }^{11}$ sobre la policitación, no obstante ser mero derecho natural, que no produce ninguna obligación, para el derecho civil daba entre los romanos, en dos casos fuerza y valor a las policitaciones que se hacían a su ciudad: en causa de un fuerte motivo para que se produjera, en consideración de alguna magistratura municipal que se había deferido ad-honorem; y en el otro caso, cuando había

\footnotetext{
${ }^{9}$ En el sentido indicado por el Dr. D Juan Manuel Blanch Nougués -Tema 22 - Concepto Romano del Contrato. Pactum, contractus y conventio cuya aplicación para el concepto de la policitación expone en 16-D.50.1.2.3 Ulpianus libro quarto disputationum

10 "Tratado de las Obligaciones. Aparte La policitación en el derecho romano" § II tomado de https://www.google.com.co/\#q=bookstratadoobligacionespothier.html

${ }^{11}$ lbid
} 
empezado a cumplirse la promesa; lo que da margen a creer que las policitaciones producen por derecho más reciente verdadera obligación (para ubicar aproximación referida a la REVOCATORIA como promesa programática de derecho público Estatal) En igual sentido y orientación Antonio Varela Stolle ${ }^{12}$ afirma: los romanos distinguían de las convenciones lo que llamaban policitación, consistente en una simple promesa no aceptada y solo producía un vínculo de derecho, en casos excepcionales y privilegiados como la hecha en favor del Estado o de una ciudad ${ }^{13}$ en cuyo caso, si el policitante había ofrecido por alguna razón especial, que llegara a tener efecto, quedaba obligado el mismo y sus herederos; y si no mediaba esta circunstancia, solo quedaba obligado, cuando había principiado a efectuarse la promesa; de otra parte, en los casos referidos a el voto ${ }^{14}$ como promesa hecha a Dios, como objeto religioso o de piedad, que solo era obligatorio jurídicamente para los herederos, si se había pronunciado materialmente, y en todo los demás casos solo producía una obligación de conciencia.

\section{POLICITACION U OFERTA EN EL ORDENAMIENTO JURIDICO MODERNO}

2.1. Breves antecedentes históricos. Abordar el tema de la policitación en el contexto del ordenamiento jurídico moderno, implica la descripción necesaria del desarrollo histórico de esta institución desde sus inicios en el derecho romano, hasta la moderna teoría, en donde se postulan los principios fundamentales que en materia de contrato y su formación implica, ya como teoría precontractual o promesa de contrato, ya como oferta o policitación que hoy comparten las distintas legislaciones del mundo, unas como teoría precontractual, otras como contrato preparatorio, teoría que de la adopción del antiguo y clásico derecho romano, se tiene en las legislaciones europeas, en especial la Suiza, Alemana, Francesa, Española e Italiana y en realidades latinoamericanas como la Mejicana y Colombiana.

En efecto, a principios del derecho romano clásico, no se contaba con la figura ya de contrato preparatorio, ya de teoría precontractual, ya de policitación, solamente eran considerados los llamados contratos strictis juris ${ }^{15}$ de exigencias rigurosas en formalidades legales, que en caso de no cumplirlas (excepcionalmente podría ocurrir) las partes carecían de acción para exigir su cumplimiento, contexto en el que la

\footnotetext{
${ }^{12}$ Ibid

${ }^{13}$ Antonio Varela Stolle, ob citada enlace de bocks htm pag 317 § 567 De la policitación indicando lo toma de Fr. 1, § 1, 2. Fr. 3, pr. Fr. 6, pr. D. 50, 12

${ }_{14} \mathrm{lbid}$, Fr. 2, D. 50,12

15 Alessandri Rodríguez Arturo, "De la compraventa y de la promesa de venta" Santiago de Chile, Editorial Jurídica de Chile, 2003, T II Vol 2 pag 830
} 
promesa de contrato futuro no encontraba cabida, y en caso de su formulación, las partes carecían de acción, situación en las que dado las necesidades crecientes de la sociedad romana ${ }^{16}$ surgían convenios similares a lo más parecido a un contrato preparatorio, oferta, promesa, las partes carecían de acción, por lo que esas manifestaciones convencionales aparecidas encontraron como primeros antecedentes históricos en los pactos (pactum) y en la stipulatio romana, mecanismos legales que más tarde permitió acción civil para cumplimiento de la obligación, alcance dado por los pretores y la jurisprudencia en ciertos casos, referidos al pactum, tales como el pacto de constituto, el de receptum, y el de juramento, que permitió entonces la distinción de los convenios (conventio) en dos tipos: los contratos (contractum) y los pactos (pactum) que no daban de manera general acción para su cumplimiento, solamente en específicos casos tenían valor legal pleno; en tanto que la stipulatio romana considerada en un sentido diferente, fue la antítesis de la promesa, fue un contrato con carácter general, formulado a través de una pregunta del acreedor y la respuesta del deudor, en términos solemnes ${ }^{17}$; cabe señalar que los casos antes descritos del derecho romano cubrían algunas necesidades jurídicas que hoy se satisfacen con el llamado contrato preparatorio, promesa u oferta, en ninguno de los casos se pretendía dar una promesa para formular un contrato futuro diferente, sino que el pactum y la stipulatio se daban como partes o accesorios de un solo convenio.

En este contexto también los romanos le dieron el tratamiento a la estipulación como ya viene dicho, entendida como una promesa aun no aceptada, pero que solamente fue valida en contados casos, como en el derecho público ${ }^{18}$ esto es cuando se hacía una promesa a una ciudad; por lo que ésta figura jurídica en términos de la doctrina y aplicabilidad practica en sentido estricto no se considera un contrato o convenio por no existir acuerdo entre las partes, en consecuencia, no es equiparable

\footnotetext{
${ }^{16}$ Ubicación histórica que consideramos corresponde a la que describe González de Cancino Emilssen en su obra Manual de Derecho Romano Publicaciones Universidad Externado de Colombia $6^{a}$ edición, página 45 así: "Durante el Siglo III y la última mitad del segundo, Roma se convirtió en una potencia en toda la cuenca del Mediterráneo....el paso de la economía agrícola primitiva a la de los grandes latifundios, aprovechados al máximo...." ( )....

${ }_{17}^{17}$ Dare Spondere? Spondeo pregunta típica del derecho romano clásico

18 González de Cancino Emilssen en su obra Manual de Derecho Romano Publicaciones Universidad Externado de Colombia $6^{\text {a }}$ edición páginas 88 y 89 afirma: El derecho primitivo y clásico romano entendían la división entre el derecho público y el derecho privado como una cuestión de esferas de influencia, sobre la base del sentido y dirección dado por la ley, como fuente de derecho, las que en los tiempos republicanos, solamente un mínimo porcentaje regula materias específicas de derecho privado, refiriéndose, la mayoría a cuestiones de organización sociopolítica y que su fuerza obligatoria depende de la inclusión de recursos procesales tendientes a darle aplicación, en los programas de los magistrados que se encargan de aplicar justicia y solucionar los litigios
} 
a un contrato preparatorio o de promesa de contrato, lo que permite afirmar que en el derecho romano no existió propiamente contrato de promesa en específico ${ }^{19}$ solo se contó con distintas figuras como las antes descritas (conventios) que se desarrollaron para satisfacer las exigencias del comercio de su tiempo.

2.2. De los conceptos generales y actuales de la Policitación en el Derecho ${ }^{20}$. Expresión derivada del latín pollicitatio-onis, promesa que aún no ha sido aceptada.) También se le llama oferta o propuesta. Es una declaración unilateral de voluntad que produce efectos jurídicos propios y vinculantes, y que seguida de una aceptación forma el consentimiento, elemento esencial del contrato. La policitación es un negocio jurídico unilateral que como tal vale y produce efectos, por sí mismo, aun cuando no llegue a coincidir con la aceptación para la integración del consentimiento.

En términos específicos suele describirse a esta figura Jurídica como una manifestación unilateral de voluntad negocial, expresa o tácita, recepticia, hecha a persona determinada presente o no presente, con o sin fijación de plazo y con la expresión de los elementos esenciales del acto jurídico cuya celebración pretende su emisor concertar. De esta descripción se desprenden como características de la policitación las siguientes:

a) Es una declaración unilateral de voluntad, porque, aun emitida por varias personas, muestra un mismo sentido o dirección.

b) Es voluntad negocial, porque es emitida con el propósito de celebrar un negocio jurídico, de crear efectos de derecho.

c) Puede ser expresa o tácita expresa cuando se manifiesta verbalmente por escrito o por signos inequívocos; tácita cuando resulta de hechos o actos que la presupongan o autoricen a presumirla.

d) Es recepticia porque siempre es dirigida a persona que la debe recibir.

e) Es hecha a persona determinada, a alguien en específico.

f) Puede ser dirigida a persona presente o no presente. Presente, esto es, con la que se tenga comunicación inmediata sea por estar en el mismo sitio policitante y receptor; sea porque encontrándose distantes encontrándose distantes puedan conocer y discutir de inmediato las condiciones del presunto acto jurídico, como sucede en la contratación por vía telefónica; no presente,

\footnotetext{
${ }^{19}$ Véase a Sánchez Medal Ramón, - De los Contratos Civiles , 20ª edición México, Porrúa, 2004 pag 137 y Alessandri Rodríguez Arturo "De la compraventa y de la promesa de venta" Santiago de Chile, Editorial Jurídica de Chile, 2003, T II Vol 2 nota 1 pag 830

${ }^{20}$ Los conceptos aquí descritos son tomados en su mayoría del Diccionario Jurídico Colombiano con enfoque en la Legislación Nacional, editora Jurídica Nacional, págs. 476 y 477. Compiladores Bohórquez Botero Luis Fernando y Jorge Ivan
} 
es decir, cuando entre policitante y destinatario de la oferta se establezca una comunicación mediata, como ocurre en el caso de la propuesta hecha por vía epistolar (contrato celebrado por correspondencia.

g) Puede ser emitida con o sin fijación de plazo para aceptarla, con determinación o sin determinación por parte del policitante de un término durante el cual estará obligado a sostener su ofrecimiento. Hay que distinguir tres situaciones: si la oferta se hace a una persona presente sin fijación de plazo, para aceptarla el policitante queda desligado si la aceptación no se hace inmediatamente (la misma regla se aplica a la oferta hecha por teléfono). Si la oferta se hace entre no presentes sin fijación de plazo, el policitante queda ligado por un término de tres días más el tiempo necesario para la ida y vuelta regular del correo público, según las distancias y la facilidad o dificultad de las comunicaciones. Por último, si la oferta es hecha fijándose un plazo para su aceptación, trátese de presentes o no presentes, la regla es única: el policitante se obliga frente al destinatario hasta la expiración del plazo, a menos que la oferta sea rechazada antes de vencer este. Debe contener los elementos esenciales del acto jurídico cuya celebración pretende el policitante la indicación de puntos suficientes y precisos para que el acto pueda perfeccionarse mediante la simple aceptación del destinatario. Así, si alguien dice "vendo casa barata", "propongo negocio ventajoso", no estará haciendo una oferta en términos de derecho. Tales ofrecimientos son actos previos a la contratación que deben distinguirse de la oferta jurídica, no sólo porque ésta es el primer momento en la formación del consentimiento, sino por las responsabilidades que pueden derivarse en cuanto que la policitación, y no así las pláticas preliminares, constituye un negocio jurídico.

La policitación puede ser retirada siempre que la retracción llegue al destinatario antes que sea propuesta. Conocida la oferta por el destinatario, si se fijó un plazo para su aceptación, la retractación sobrevenida antes de la extinción de este plazo será inoperante, y la aceptación ocurrida vigente la propuesta operará la formación del contrato. -En la oferta se trata precisamente de uno de los preliminares del acto contractual que debe o no celebrarse como consecuencia de ella. (...) Según nuestro Código Civil, el contrato resulta del concurso real de las voluntades de dos o más personas, esto es, de su consentimiento. Más, el Código no ha dicho cómo debe prestarse el consentimiento; y hemos debido recurrir a la teoría y a las reglas del Derecho Comercial para determinar cómo se forma el consentimiento hasta quedar perfeccionado el contrato. Hemos establecido así que su formación resulta de dos actos sucesivos: una de las partes inicia la negociación y manifiesta primero su 
voluntad proponiendo a la otra las bases del contrato que proyecta lo que constituye la oferta; y la otra acepta la proposición que se le hace por medio de la aceptación, que para simplificar suponemos pura y simple y conformen todas sus partes con la ofertall. (...) El proponente, en seguida, está obligado a ejecutar su promesa si es aceptada en tiempo oportuno. Esta obligación es distinta del contrato mismo y nace también de su sola voluntad. ¿Si antes de la aceptación el proponente cambia de parecer y cuando le llega la aceptación no quiere ya ejecutar lo ofrecido, queda desarmado el aceptante que dio su aceptación oportunamente? No puede menos de llegarse a la conclusión de que el proponente está obligado por su sola promesa, por su sola declaración de voluntad. La oferta se presenta así como un hecho jurídico que engendra sus conclusiones propias $^{21}$

En Colombia la oferta se encuentra regulada en el código de Comercio artículos 845 a $860^{22}$ normatividad que de manera general la regula como proyecto de

\begin{abstract}
${ }^{21}$ Véase ob cit Diccionario Jurídico Colombiano con enfoque en la Legislación Nacional, editora Jurídica Nacional, págs. 477 y 478. Compiladores Bohórquez Botero Luis Fernando y Jorge Iván

22 Código de Comercio Colombiano tema regulatorio de la Oferta ART. 845. - La oferta o propuesta, esto es, el proyecto de negocio jurídico que una persona formule a otra, deberá contener los elementos esenciales del negocio y ser comunicada al destinatario. Se entenderá que la propuesta ha sido comunicada cuando se utilice cualquier medio adecuado para hacerla conocer del destinatario.ll -ART. 846. - La propuesta será irrevocable. De consiguiente, una vez comunicada, no podrá retractarse el proponente, so pena de indemnizar los perjuicios que con su revocación cause al destinatario. La propuesta conserva su fuerza obligatoria aunque el proponente muera o llegue a ser incapaz en el tiempo medio entre la expedición de la oferta y su aceptación, salvo que de la naturaleza de la oferta o de la voluntad del proponente se deduzca la intención contraria.ll -ART. 847.- - Las ofertas de mercaderías, con indicación del precio, dirigidas a personas no determinadas, en circulares, prospectos o cualquiera otra especie similar de propaganda escrita, no serán obligatorias para el que las haga. Dirigidas a personas determinadas y acompañadas de una nota que no tenga las características de una circular, serán obligatorias si en ella no se hace salvedad alguna.ll -ART. 848. - Las ofertas que hagan los comerciantes en las vitrinas, mostradores y demás dependencias de sus establecimientos con indicación del precio y de las mercaderías ofrecidas, serán obligatorias mientras tales mercaderías estén expuestas al público. También lo será la oferta pública de uno o más géneros determinados o de un cuerpo cierto, por un precio fijo, hasta el día siguiente al del anuncio.ll -ART. 849. - Cuando en el momento de la aceptación se hayan agotado las mercaderías públicamente ofrecidas, se tendrá por terminada la oferta por justa causa.ll -ART. 850. - La propuesta verbal de un negocio entre presentes deberá ser aceptada o rechazada en el acto de oírse. La propuesta hecha por teléfono se asimilará, para los efectos de su aceptación o rechazo, a la propuesta verbal entre presentes.ll -ART. 851.-Cuando la propuesta se haga por escrito deberá ser aceptada o rechazada dentro de los seis días siguientes a la fecha que tenga la propuesta, si el destinatario reside en el mismo lugar del proponente; si reside en lugar distinto, a dicho término se sumará el de la distancia.ll -ART. 853.-Las partes podrán fijar plazos distintos a la aceptación o rechazo de la propuesta o ésta contenerlos.ll -ART. 854.-La aceptación tácita, manifestada por un hecho inequívoco de ejecución del contrato propuesto, producirá los mismos efectos que la expresa, siempre que el proponente tenga conocimiento de tal hecho dentro de los términos indicados en los artículos 850 a 853, según el caso.ll —ART. 855.—-La aceptación condicional o extemporánea será considerada
\end{abstract}


negocio jurídico cuyos requisitos son la intención de producir un vínculo jurídico y que dicha intención sea exteriorizada, ya expresa o tácitamente, debe además ser completa la oferta o sea, que sea explicada de tal forma que para el nacimiento del

como nueva propuesta.ll -ART. 856.-La oferta pública de una prestación o premio será obligatoria siempre que se cumplan las condiciones en ella previstas. y no señala el término para comunicar el cumplimiento de tales condiciones, la cuyos requisitos son la intención de producir un vínculo jurídico y que dicha intención sea exteriorizada, ya sea expresa o tácitamente, debe además ser completa la oferta o sea, que sea explicada en tal forma que para el nacimiento del contrato sólo baste con que la persona a quien se dirige, diga — síll; debe ser voluntaria, dirigida a un destinatario y ser comunicada a éste por un medio útil.ll Para la doctrina la propuesta de contrato debe reunir los siguientes requisitos: 1) ha de ser emitida con la intención de obligarse el oferente contractualmente; 2) ha de ser concreta, de tal manera que contenga todos los elementos esenciales necesarios para la conclusión del contrato; 3 ) por regla general debe ser dirigida a la persona con la cual el proponente quiere concluir el contrato

La oferta es la declaración de voluntad que busca obtener la celebración de un contrato. De este modo, quien emite la oferta es denominado el —oferentell y quien posteriormente la acepta será el -aceptantell. A esta conjunción de oferta y aceptación se le denomina —consentimientoll en su aspecto de forma.

El término oferta ha recibido diverso tratamiento en la doctrina y muchas veces ha sido confundido con otros de similar naturaleza con los que, si bien es cierto, guarda elementos comunes, también tiene diferencias sustanciales. Así, podemos encontrar que en la teoría jurídica la oferta ha sido comparada con otros dos términos: - propuestall y - policitaciónll.

Respecto de la policitación, si bien ciertas doctrinas española y francesa modernas la entienden equivalente al término -ofertall, ésta recibe tres contenidos marcadamente diferentes; algunos consideran que la policitación es aquella declaración dirigida a personas no determinadas, es decir, carecía de un destinatario preciso; mientras que la oferta está dirigida a persona determinada; otros, entienden que ambas voces no son sinónimas ya que mientras la policitación es la oferta no aceptada, la oferta propiamente dicha es aquella que obligación del oferente cesará transcurrido un mes desde la fecha de la oferta, salvo que de la naturaleza de ésta se deduzca un término distinto.II -ART. 857.- - La oferta pública sólo podrá revocarse, antes del vencimiento del término de la misma, por justa causa. La revocación deberá ponerse en conocimiento del público en la misma forma en que se ha hecho la oferta o, en su defecto, en forma equivalente. La revocación no producirá efectos con relación a la persona o personas que hayan cumplido ya las condiciones de la oferta.ll -ART. 858.-Si las condiciones de la oferta se cumplen separadamente por varias personas, sólo tendrá derecho a la prestación ofrecida aquella de quien el oferente primero reciba aviso de su cumplimiento. En caso de igualdad en el tiempo, el oferente decidirá en favor de quien haya cumplido mejor las condiciones de la oferta, pudiendo partir la prestación, si ésta es divisible. $\mathrm{Si}$ las condiciones son cumplidas por varias personas en colaboración, la prestación se dividirá entre ellas, si su objeto es divisible; en caso contrario, se seguirán las reglas del Código Civil sobre las obligaciones indivisibles.ll -ART. 859. -El oferente no podrá utilizar las obras ejecutadas por las personas excluidas de la prestación ofrecida. Si lo hiciere, deberá en todo caso indemnizarlas.ll -ART. 860. -En todo género de licitaciones, públicas o privadas, el pliego de cargos constituye una oferta de contrato y cada postura implica la celebración de un contrato condicionado a que no haya postura mejor. Hecha la adjudicación al mejor postor, se desecharán las demás.ll Tomado de www.todoiure.com.ar/.../mono/civil/la oferta en los contratos.html 
contrato solo baste con que la persona a quien se dirige, diga "si"; debe ser voluntaria, dirigida a un destinatario y ser comunicada a éste por un medio útil "

Para la doctrina la propuesta de contrato debe reunir los siguientes requisitos: 1) ha de ser emitida con la intención de obligarse el oferente contractualmente; 2) ha de ser "concreta, de tal manera que contenga todos los elementos esenciales necesarios para la conclusión del contrato; 3 ) por regla general debe ser dirigida a la persona con la cual el proponente quiere concluir el contrato.

La oferta es la declaración de voluntad que busca obtener la celebración de un contrato. De este modo, quien emite la oferta es denominado el "oferente" y quien posteriormente la acepta será el "aceptante". A esta conjunción de oferta y aceptación se le denomina "consentimiento" en su aspecto de forma.

El término oferta ha recibido diverso tratamiento en la doctrina y muchas veces ha sido confundido con otros de similar naturaleza con los que, si bien es cierto, guarda elementos comunes, también tiene diferencias sustanciales. Así, podemos encontrar que en la teoría jurídica la oferta ha sido comparada con otros dos términos: "propuesta" y "policitación".

Respecto de la policitación, si bien ciertas doctrinas española y francesa modernas la entienden equivalente al término "oferta", ésta recibe tres contenidos marcadamente diferentes; algunos consideran que la policitación es aquella declaración dirigida a personas no determinadas, es decir, carecía de un destinatario preciso; mientras que la oferta está dirigida a persona determinada; otros, entienden que ambas voces no son sinónimas ya que mientras la policitación es la oferta no aceptada, la oferta propiamente dicha es aquella que ha sido aceptada y forma el contrato; en este caso, el elemento diferenciador de una y otra figura viene dada por la aceptación del destinatario, y la tercera posición que postula que la policitación es aquella propuesta que no ha llegado a conocimiento del destinatario mientras que la oferta si ha sido conocida.

De este modo, concluimos que en doctrina se entiende que la propuesta comprende tanto a la oferta como a la policitación y le ofrece un tratamiento distinto.

3.- Planteamiento del enfoque aproximado y aplicado de la Policitación en el concepto del tema de derecho Público en Colombia "Revocatoria de mandato de las autoridades locales en Colombia" como se ha indicado antes, se pretende a manera de inquietud académica explicar la validez de aplicabilidad del concepto de la policitación desde la óptica del derecho comparado y su conexión con la legislación moderna del derecho público y cuyo enfoque queremos se entienda aplique al igual, al 
menos en el sentido de interpretación, tal y cual ocurrió con la adopción en el ordenamiento civil- comercial o de derecho privado en las legislaciones del mundo de esa figura del derecho romano; mas no para el derecho público, y en especial en el entendido de la revocatoria de mandato de las autoridades territoriales (municipales) de elección popular.

En efecto, la premisa de la tesis basa su acerbo conceptual de manera general en el libro quarto disputationum Ulpianus 16-D.50.1.2.3 del tenor ${ }^{23}$ :

El pacto es el consentimiento y la convención de dos, la policitación es en cambio la promesa del solo oferente. Y por ello se ha establecido que si hubiese sido hecha una policitación (promesa unilateral) para obtener un cargo, se exija como deuda. Pero también la obra iniciada, aunque no fuera prometida para la obtención de un cargo, el promitente se obliga a terminarla, y así ha quedado establecido.

$1 \mathrm{Si}$ alguien desea reivindicar el objeto que ha entregado en virtud de la policitación a los munícipes, debe ser rechazado en su petición: esto es muy justo pues semejantes voluntades conferidas a las ciudades no se revocan por arrepentimiento. También, incluso, si los munícipes dejaran de poseer, se ha de decir que ha de concedérseles acción. (Subrayas fuera del texto para connotar sobre la tesis del planteamiento), el alcance de la figura que al parecer y en el decir de la profesora Emilssen González de Cancino ${ }^{24}$ en el análisis que de la crisis del Estado Noble Patricio-Plebeyo hace, frente al paso de la economía agrícola primitiva a la de los grandes latifundios, y las connotaciones económicas sociales que ello genera como potencia del mediterráneo que fue Roma, presionaron la necesidad de definir la estructura del Estado, de manera tal que su constitución Republicana que funcionaba para una ciudad, fuese capaz de organizar el imperio, sentando de manera paulatina una forma política diferente, que se manifiesta y referencia González de Cancino ${ }^{25}$ con el movimiento de los gracos, cuyos cambios consistieron en introducir la idea de que la soberanía reside sin restricciones, en el pueblo, ello con ocasión de la negación

${ }^{23}$ Véase Blanch Nogués Juan Manuel -Tema 22 Concepto Romano del Contratoll 16-D D.50.1.2.3 Ulpianus libro quarto disputationum, base del enfoque aplicado y aproximativo de este ensayo: pr. Pactum est duorum consensus atque conventio, pollicitatio vero offerentis solius promissum. Et ideo illud est constitutum, ut, si ob honorem pollicitatio fuerit facta, quasi debitum exigatur. Sed et coeptum opus, licet non ob honorem promissum, perficere promissor eo cogetur, et est constitutum. 1. Si quis quam ex pollicitatione tradiderat rem municipibus vindicare velit, repellendus est a petitione: aequissimum est enim huiusmodi voluntates in civitates collatas paenitentia non revocari. Sed et si desierint municipes possidere, dicendum erit actionem eis concedendam.

${ }^{24}$ En su obra Manual de Derecho Romano Publicaciones Universidad Externado de Colombia 6 ${ }^{\mathbf{a}}$ edición página 45 .

${ }^{25}$ ob cit págs. 48 y 49 
que de la propuesta agraria de Tiberio hiciera el Senado; de una parte; de la otra, cuando se solicita a los comicios la expulsión de un colega de tribunado que se opone a las reformas, la idea de que tribunos y magistrados representan al pueblo, que les puede REVOCAR su mandato cuando no actúen de acuerdo con los intereses del representado, se aplica la figura con criterios de entenderla en su connotación de mandato popular.

De manera general, se afirma, siguiendo al profesor Noguera Laborde Rodrigo ${ }^{26}$ que los romanos fueron los creadores del derecho, siendo acertados en establecer su división en natural ${ }^{27}$ de gentes ${ }^{28}$ y positivo y éste último en público y privado; aquel, es decir, el público en la estructura de gobierno del principado, dado que éste no era hereditario, para resolver el problema de la sucesión recogió de la institución de familia la ADOPCION y adecuándola a los fines del derecho público que pretendían obtener, de los cuales el principal fin era la transmisión del poder público ${ }^{29}$.

En igual sentido en que nos referimos a la distinción del derecho positivo en público y privado del derecho romano, ya en los tiempos republicanos el término ley (lex), cuyo sentido amplio apunta a la dirección o instrucción sobre el comportamiento a seguir, prescrita por una persona privada o por el Estado, en su sentido político designa las órdenes públicas dictadas por el Estado y sus funcionarios obligatorias para otros ${ }^{30}$; distinguiendo entonces su división como una cuestión de esferas de influencia; por lo que, será ley privada, la que emane de una persona privada (el pater por ejemplo) su eficacia por tanto se limita al ámbito de potestad sobre los bienes o sobre los individuos o sobre los individuos a ellos sometidos; será ley pública la que emane de un organismo público (comicios), cuya eficacia va dirigida a todos los ciudadanos.

Las distinciones entre leyes públicas y leyes privadas y entre derecho público y privado no tienen hoy en el derecho moderno la misma significación que tuvo en su tiempo el derecho primitivo y clásico romano, pero ello apunta a precisar que ellas constituyen autentica fuentes del derecho, producto bien de actos o hechos pasados

\footnotetext{
${ }^{26}$ Introducción General al Derecho Vol. I Introducción a la Filosofía del Derecho $2^{2}$ edición serie Major-3 USA 1996 pág 24

${ }^{27}$ Dig., I, 1,3

${ }^{28}$ Inst., $1,1,11$.

${ }^{29}$ Para los romanos era el ius civile como el propio de cada ciudad. Más detalles al respecto véase González de Cancino Emilssen Manual de Derecho Romano Publicaciones Universidad Externado de Colombia $6^{\text {a }}$ edición página 59

30 Véase a Francisco Samper Polo, Derecho romano Valparaiso, Ediciones Universitarias de Valparaiso, pág 16 cita que hace González de Cancino Emilssen Manual de Derecho Romano Publicaciones Universidad Externado de Colombia 6 $6^{\underline{a}}$ edición página 89
} 
de los que deriva la creación, modificación o extinción de normas jurídicas, comprendiendo en este sentido el principio u origen de una norma, así como el lugar donde nace o se produce algo; por tanto cuando el espacio geográfico de creación, aplicación o interpretación de la norma se extiende por encima de las fronteras territoriales creando circuitos y microcircuitos normativos entre los sistemas jurídicos nacionales, binacionales, regionales y globales, con la multiplicidad de sujetos intervinientes en el proceso de regular las variadas y novedosísimas situaciones políticas, económicas y sociales que de ese proceso derivan, lo que para el caso que nos ocupa, da por sentado la necesidad de la labor interpretativa y lo más importante dentro del tema de la recepción o transfusión, valorar el conocimiento del derecho romano como instrumento de utilidad manifiesta para adelantarla, en el marco del cual asimilamos el caso de la policitación en su sentido público y político con la REVOCATORIA del mandato de las autoridades territoriales en Colombia, con lo cual reafirmo la esencia romanística de la elaboración de la figura que no es nueva, pero que la recepción de la figura solo pervive hoy en el derecho civil y comercial aplicado.

3.1. FUNDAMENTOS DE LA REVOCATORIA ${ }^{31}$ [28] La revocatoria de mandato se fundamenta en los principios de soberanía popular y de representación, puesto que el pueblo en ejercicio de su soberanía, otorga a sus representantes un mandato para que ejerzan el poder político.

La Constitución de 1991 estableció que los Gobernadores y los Alcaldes contraen con sus electores la obligación de cumplir el programa de gobierno que presentaron al inscribirse como candidatos $y$, en tal sentido, reciben mandato del elector. El incumplimiento del programa equivale al quebrantamiento del mandato, circunstancia que da lugar a que su elección pueda ser revocada por decisión popular (artículo 259). Este régimen no se aplica a los miembros de las corporaciones públicas.

La revocatoria del mandato ha sido consagrada en el artículo 103 de la Carta como un mecanismo de participación ciudadana y en el artículo 40 como un derecho político. El artículo 6 de la ley 134 de 1994 precisa que "La revocatoria del mandato es un derecho político por medio del cual los ciudadanos dan por terminado el mandato que le han conferido a un gobernador o a un alcalde".

La revocatoria del mandato, que se promueve a iniciativa de los ciudadanos, tiene un carácter plebiscitario, en sentido negativo, pues apunta a censurar o retirar la confianza del público al elegido y, con ello, precipitar su forzoso retiro del cargo

31 Tomado de http://huitoto.udea.edu.co/derecho/constitucion/revocatoria mandato.html 
Con este mecanismo, previsto en la Ley 134 de 1994 y pocas veces utilizados por los electores en provincia, se podría corregir el rumbo de un municipio o de un departamento, ante "la insatisfacción general de la ciudadanía o por el incumplimiento del programa de gobierno" del respectivo alcalde o gobernador. Con una ventaja: la norma citada es de las pocas en Colombia cuyas disposiciones son claras, cortas y precisas. Un número de personas, igual o mayor al $40 \%$ del total de los votos válidos con los cuales se eligió el respectivo gobernante, pueden pedir a la Registraduría respectiva la citación a una elección con el fin de que el pueblo se exprese sobre la revocatoria del mandato. Dicho formulario de solicitud deberá contener las razones sobre las cuales los descontentos basen su petición. El registrador del caso, después de aprobada la solicitud y expedida la certificación propia, convocará, dentro de los dos meses siguientes, a la votación para la revocatoria. La revocatoria se considerará aprobada si así lo votaren el $60 \%$ o más de las personas participantes en la elección, siempre y cuando el número total de votos (incluidos los nulos y los en blanco) fuere igual o superior al $60 \%$ del total de votos consignados el día en el cual se eligió al mandatario, aclarando que "únicamente podrán sufragar quienes lo hayan hecho en la jornada electoral en la cual se eligió al respectivo gobernador o alcalde". Si se aprueba la revocatoria, el Presidente o el Gobernador, según sea el caso, deberá, inmediatamente, ejecutar la orden popular y remover el respectivo Alcalde o Gobernador y se procederá a convocar nuevas elecciones para la escogencia del nuevo mandatario, dentro de los treinta días siguientes a la certificación de los resultados de la votación de revocatoria. En todo caso, la revocatoria no podrá efectuarse si aún no transcurre siquiera el primer año de mandato del Alcalde o Gobernador atacado. Podrá inscribirse como nuevo candidato a esos cargos cualquier persona que cumpla los requisitos constitucionales y legales, salvo el alcalde renunciante 0 el revocado. La inscripción deberá efectuarse ante el respectivo registrador y con una antelación no inferior a veinte días contados desde el día de las votaciones para la revocatoria.

Como vemos, el procedimiento es simple, relativamente corto y bien descrito por la Ley. Por ello cabe la pregunta: ¿por qué razón la gente no lo utiliza? No será, precisamente, porque los elegidos, todos, sean tan buenos. Debe ser, mejor, porque este instrumento no es bien conocido y porque, al fin y al cabo, se trata de una elección contra alguien defendiéndose, directamente, con el ipresupuesto y la nómina oficiales! También, el hecho de haber ratificado "mayoritariamente" a los gobernantes cuestionados en todas las utilizaciones del mecanismo, ha influido negativamente en la gente. Una última razón podría ser la falta de disposición de todo el mundo para reconocer los errores cometidos. 
De todas formas, el instrumento está allí, dispuesto a servirle al pueblo para corregir sus destinos. Claro, como me lo dijo un amigo hace poco, de la revocatoria también podrían también podrían servirse los politiqueros de siempre para terminar imponiendo una decisión no querida realmente por la comunidad. La respuesta es igual de simple: jla decisión "querida realmente", en este caso, es la tomada en las urnas!

Por otro lado, también queda a los gobernantes la fácil decisión de corregir las fallas de su administración, jantes que el pueblo escoja corregir su error!

Para concluir, podemos decir que: 1. La aproximación hecha, constituye una apreciación de carácter técnico, sobre la base y necesidad de abandonar el análisis exclusivamente normativo que en el derecho civil y comercial tiene hoy la figura de la Policitación, las que desde la perspectiva del razonamiento jurídico fundado en los principios generales del derecho, comprendiendo la relatividad de los puntos de vista respecto del tema y su adopción integral, aplicados al derecho público referidos a la revocatoria del mandato de las autoridades del orden territorial en Colombia.

2. La figura de la policitación tomada del más antiguo derecho romano clásico, tiene su explicación aproximada y deviene de los términos contrahere y contractus, que desde ese periodo, siendo claras las distinciones entre CONTRATO Y PACTO, no indicaban ser fuentes de las que nace la obligación, sino la propia obligación.

3. La policitación, no obstante ser mero derecho natural, que no produce ninguna obligación, para el derecho civil daba entre los romanos, en dos casos fuerza y valor las que se hacían a su ciudad: en causa de un fuerte motivo para que se produjera, en consideración de alguna magistratura municipal que se había deferido ad-honorem; y en el otro caso, cuando había empezado a cumplirse la promesa; lo que da margen a creer que las policitaciones producen por derecho más reciente verdadera obligación.

4. Es una afirmación categórica y cierta, que los creadores del derecho, son los romanos, que dividieron en natural, de gentes y positivo, éste último en público y privado; el público, el cual tiene que ver con la estructura de gobierno, y/o tipo de Estado que corresponde al principado, dado que éste no era hereditario, para resolver el problema de la sucesión recogió de la institución de familia la ADOPCION y la adaptaron a los fines del derecho público que pretendían obtener, de los cuales el principal era la transmisión del poder público.

5. La policitación en su sentido público y político iniciales del derecho romano clásico, tiene una relación directa con la REVOCATORIA del mandato de las 
autoridades territoriales en Colombia, con lo cual se reafirma la esencia romanística de la figura que no es nueva, pero que la recepción solo pervive hoy en el derecho civil y comercial aplicado, y no en el derecho público, deferido a la ley.

\section{Referentes bibliográficos}

Alessandri Rodríguez Arturo, "De la compraventa y de la promesa de venta" Santiago de Chile, Editorial Jurídica de Chile, 2003, T II Vol 2 pág 830

Bohórquez Botero Luis Fernando y Jorge Ivan, Diccionario Jurídico Colombiano con enfoque en la Legislación Nacional, editora Jurídica Nacional,

Blanch Nougués Juan Manuel "DERECHO COMPARADO DE LAS OBLIGACIONES" -Tema 22 Concepto Romano del Contratoll 16-D D.50.1.2.3 Ulpianus libro quarto disputationum, base del enfoque aplicado y aproximativo de este ensayo, material bajado de la web de USA, Bogotá Noviembre 2011

García Villegas Mauricio, "Función simbólica del derecho y estabilidad institucional", en: Cristina Motta Ética y conflicto: lecturas para una transición democrática, Bogotá, Ed. Uniandes y Tercer Mundo, 1995

González de Cancino Emilssen Manual de Derecho Romano Publicaciones Universidad Externado de Colombia 6ª edición. Bogotá

Noguera Laborde Rodrigo, Introducción al Derecho Volumen I Introducción a la Filosofía del Derecho 2ª edición serie Major-3 USA 1996

Pothier Robert Joseph, Tratado de las Obligaciones. Aparte La policitación en el derecho romanoll $\S$ II tomado de bookstratadoobligacionespothier.htm

Sánchez Medal Ramón, —De los Contratos Civiles, 20ª edición México, Porrúa, 2004

Samper Polo Francisco, Derecho Romano Valparaiso, Ediciones Universitarias de Valparaiso.

Varela Stolle Antonio -Explicaciones históricas elementales del derecho romanoll tomado de bocks html pág 317 § 567 De la policitación

\section{Sitios Web}

http://huitoto.udea.edu.co/derecho/constitucion/revocatoria_mandato.html

http://www.banrepcultural.org/blaavirtual/revistas/credencial/marzo2003/cuando.html 